Available online on 15.12.2019 at http://jddtonline.info
Open Access to Pharmaceutical and Medical Research
unrestricted non-commercial use, provided the original work is properly cited

Open $\odot$ Access

Research Article

\title{
Attitude and Practice of Community Pharmacists towards Pharmaceutical Care in Nigeria
}

\author{
Amibor Kingsley Chiedu' ${ }^{1}$, Okonta Collins ${ }^{2}$ \\ ${ }^{1}$ Federal Medical Centre, Asaba \\ 2 El-Rapha Pharmacy Ltd, Okpanam, Delta State
}

\begin{abstract}
Background: Since the introduction of pharmaceutical care in the 1990's, a lot of progress has been made, but misconceptions and barriers to its full implementation still exist. Around the world, community pharmacists are moving from supplying and dispensing medications to gradual introduction of pharmaceutical care into their practice.

Objectives: This study evaluated the attitude and practice of pharmaceutical care among community pharmacists in Delta State, Nigeria.

Methods: These were achieved through the use of a 30 item questionnaire pretested and administered to 50 community pharmacists that gathered for their quarterly meeting in Asaba, Delta State. Questions were in four parts, first part assessed demographics of respondents, second part was on attitude to pharmaceutical care, third part focused on practice and the fourth part was on barriers to practice and how to overcome them. Data were analyzed through chi square statistics using SPSS 23. A P-value of less than 0.05 was considered statistically significant.

Results: Out of 50 questionnaires distributed, 32 were returned, giving a response rate of $64 \%$. Majority of the respondents (28.1\%) were aged $50-59$ years, more than half (62.5\%) were males. The mean age was 40.5 years \pm 13.7 years. Majority of the respondents (71.9\%) were married, more than half (56.3\%) had Bachelor of Pharmacy as sole degree. Half (50.0\%) were residing in Warri while more than a third (40.6\%) had been in practice for 1-5 years. Attitude was positive (51.2\%), practice was poor (39.0\%). Reasons for not practicing pharmaceutical care ranged from lack of personnel (21.9\%), lack of collaboration with other healthcare providers; lack of space and non-acceptance by physicians and nurses were $18.8 \%$ each, lack of pharmaceutical care skills (9.4\%) and pharmaceutical care is time consuming (6.5\%). Analy sis of educational status versus number of respondents involved in identification of errors was significant at $\chi^{2}=21.013, \mathrm{P}=0.002$ with Bachelor of Pharmacy respondents (56.3\%) identifying most errors.
\end{abstract}

Conclusion: Attitude of community pharmacists to pharmaceutical care from this study was positive while practice was poor. Interventions such as update lectures to improve awareness of Pharmaceutical care and further attitudinal change are recommended.

Keywords: pharmaceutical care, community pharmacists, attitude and practice

Article Info: Received 12 Oct 2019; Review Completed 24 Nov 2019; $\quad$ Accepted 04 Dec 2019; Available online 15 Dec 2019

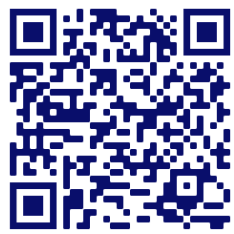

Cite this article as:

Amibor KC, Okonta C, Attitude and Practice of Community Pharmacists towards Pharmaceutical Care in Nigeria, Journal of Drug Delivery and Therapeutics. 2019; 9(6-s):164-171 http://dx.doi.org/10.22270/jddt.v9i6-s.3786

*Address for Correspondence:

Kingsley Chiedu Amibor PharmD, MPH, FPCPharm, Pharmacy Department, Federal Medical Centre, Asaba

\section{INTRODUCTION}

Much progress has been achieved since the introduction of pharmaceutical care in 1990; an innovative approach to contemporary pharmacy practice. Pharmaceutical care is the responsible provision of drug therapy for the purpose of achieving definite outcomes which improve a patient's quality of life.1,2,3,4,5 These outcomes include cure of disease, elimination or reduction of patient's symptoms, arresting or slowing of a disease process or preventing a disease. In Pharmaceutical care, the pharmacist cooperates with the patient and other professionals in designing, implementing, and monitoring a therapeutic plan that will produce specific therapeutic outcomes for the patient. ${ }^{2}$ Pharmaceutical care practices all over the world are quite diverse because of the different languages and legal, political and healthcare systems in the nations involved. ${ }^{4}$ In China, the implementation of pharmaceutical care in Chinese hospital pharmacies continues to spread, whereas it has not been a priority of community pharmacy. In Nigeria, pharmaceutical care is still at developmental stage. ${ }^{6}$

A community pharmacy is a health care facility that specializes in providing pharmaceutical services to the 
community or people at the grass root. They serve the society in the area of provision of drug products and various pharmaceutical services related needs. They are a unique hybrid of professionalism, business and health care. Community pharmacists dispense pharmaceuticals; provide counseling services on over the counter drugs and prescriptions, and advice on use of medical equipment and home care supplies. They are also involved in health education of patients on dietary habits, lifestyle changes, personal and environmental hygiene. Community pharmacies include corporately owned chain pharmacy shops, pharmacy departments in supermarkets or independently owned pharmaceutical shops that provide prescription services plus lines of health related products. ${ }^{7}$ Community pharmacies service out of stock prescriptions from government hospitals. Community pharmacists are the most easily accessible healthcare professionals to the public. ${ }^{8}$ Not all community pharmacy premises in Nigeria carry out pharmaceutical care functions. A few chain pharmacies carry out medication profiling, a complete and comprehensive summary of consumers current medications. There are still barriers that hinder the provision of pharmaceutical care that have to be overcome. For example, supermarkets and pharmacy chains, seem to put little emphasis on care provision. ${ }^{4}$ Lack of involvement of pharmacists is one of the barriers to effective implementation of pharmaceutical care services in community pharmacies in Nigeria. ${ }^{7}$ Others are limited consulting time, lack of private counseling area at the community pharmacies, perception that patients are not willing to pay for specialized care, unfriendly interprofessional dispositions and lack of enforcement of standards for pharmacists in their daily practice. 7, 9,10,11,12 In Nigeria, some community pharmacists do not have pharmacists covering the premises throughout the period the premises are open, because of inadequate manpower. Moreover, in community pharmacy setting, the pharmacist has limited or no interactions with other healthcare workers in Nigeria. These factors have not only compromised the early implementation of pharmaceutical care in community pharmacies in Nigeria, but have had negative impact on clinical pharmacy practice in the health care delivery system in Nigeria.

Various studies have been conducted on the attitude, and practice of pharmaceutical care in Nigeria and elsewhere in the world. A study carried out in Asaba among pharmacists revealed poor knowledge, weak attitude and poor practice. ${ }^{13}$ Another study carried out to in New Zealand found out that over $60 \%$ of pharmacists surveyed had a correct understanding of pharmaceutical care and that the future of pharmacy would depend on the provision of services other than dispensing. 14 Barriers to implementation identified were insufficient time, absence of reimbursement system, lack of therapeutic knowledge, clinical problem solving skills, finance, appropriate space, patient demand, access to patient medical records, and data on the value of pharmaceutical care. $^{14}$ A study carried out in China ${ }^{15}$ showed that respondents spent most of their work time performing prescription checks and providing patients with directions for drug administration, dosage, and precautions, but they tended to ignore health promotion within and outside of pharmacy settings. Factors influencing the implementation of pharmaceutical care were: lack of external conditions for developing or providing pharmaceutical care, lack of time and skills, absence of information and economic incentive, and lack of full support from other health professionals. ${ }^{15}$

A study carried out in 200316 showed that the attitudes of Nigerian pharmacists towards Pharmaceutical care were favorably high irrespective of practice settings. Earlier in
2002, some elements of pharmaceutical care activities such as medication history taking, blood pressure measurement among others was reported to have been practiced by some community pharmacists in Benin City. ${ }^{17}$ Low satisfaction of patients with pharmaceutical services without pharmaceutical care has been reported as well. A study in Kaduna reported a deficit in practice of pharmaceutical care, a positive attitude towards pharmaceutical care and lack of competence to practice pharmaceutical care. ${ }^{18}$ Community pharmacy practice is largely underdeveloped in Nigeria. ${ }^{7}$ Limited studies explored the role of pharmaceutical care in community pharmacies in Nigeria. ${ }^{13}$, 18,19,20 Studies conducted in other countries provide insight on these issues. ${ }^{21}, 22,23,24,25,26,27,28,29,30,31,32$ Another study suggested that pharmaceutical care services provided to hypertensive patients showed improved blood pressure control and overall patients satisfaction with pharmaceutical care services. $^{33}$ This underscores the potentials of community pharmacies at improving health care services. Another study carried out in Ogun State concluded that attitude of pharmacists towards implementation of pharmaceutical care was good but the ability to implement it was weak. ${ }^{20} \mathrm{~A}$ study carried out to determine the extent of counseling services in community pharmacies, revealed that $25 \%$ of pharmacists never talked with their patients while $47 \%$ of all patients never received any oral drug information from pharmacy staff. 7

The objectives of this study were to determine the attitude and practice of pharmaceutical care among community pharmacists in Delta State and to identify barriers to the implementation of pharmaceutical care.

\section{METHODS}

The study was carried out among community pharmacists practicing in Delta State, mid-Western Nigeria, as they gathered for the quarterly meeting of their association in the state capital in 2017. Delta State is one of the 36 states in Nigeria, and was created in 1991 . The state has a population of 4,112,445, comprising 2,069,309 males and 2, 043,136 females $34,35,36$ and was created on 27th August, 1991, with Asaba as the capital. She is one of the oil producing states of the country and also an agricultural state. Other mineral deposits in the state include lime, kaolin, laterite and clay. The state is situated in the South South Geo-Political Zone of Nigeria, with Warri as the biggest commercial city and Asaba as the state capital. Asaba is strategically located on a hill, at the Western edge of the majestic River Niger. The Historic River Niger is a trans- West African link beginning from the Futa Jalon highlands in Guinea and empties into the Atlantic Ocean in the Niger Delta region of Nigeria. ${ }^{37}$ The greater Asaba occupies a land mass of over 300 square kilometers. Since becoming the Delta State capital, Asaba has grown in population from the last census figure of $149,603^{38}$ in 2006. The people are very hospitable, and Asaba now maintains a cosmopolitan population of predominantly non-indigenous people. ${ }^{37}$ The state has 25 local government areas, about 58 secondary healthcare institutions, over 100 primary health care centres and a teaching hospital owned by the state government at Oghara, in Ethiope Local Government area of the state. and a Federal Medical Centre based in Asaba, a tertiary institution owned by the federal government. There are over 150 community pharmacies in the state, with majority practicing in Warri, the most densely populated town in the state, reputed to have over 80 community pharmacies and with a population of 311,97038 from national population figures of 2006, while Asaba has about 30 registered pharmacies. The remaining 40 community pharmacies are spread over the remaining towns in the state such as Sapele, Ughelli, Agbor and Abraka. The registered 
pharmacists in the state have an association known as the Association of Community Pharmacists of Nigeria (ACPN) Delta State Branch, divided into 2 zones, Warri zone and Asaba zone, because of the large land mass of the state and for ease of access of members; members are registered into each zone based on proximity. The Association rotates meetings between the zones from time to time. It was at one of such meetings in Asaba Zone that the interviews were conducted.

\section{Study population}

The study population comprised 50 community pharmacists that came from all over Delta State to attend a scheduled meeting of the Delta State Branch of the Association of Community Pharmacists of Nigeria at Asaba, the state capital.

\section{Sampling method}

Well structured, self-administered questionnaires were randomly distributed to 50 community pharmacists that gathered for their general meeting. Consent to undertake the study was sought and obtained from the leadership of the Association of Community Pharmacists of Nigeria, Delta State Branch. Also, informed consent was sought and obtained from respondents before they received the questionnaires. A pretest was carried out randomly among 10 pharmacists in Asaba, after which minor errors in typing were corrected, before the corrected questionnaires were administered to the general respondents..

\section{Data collection and analysis}

A total number of 50 questionnaires were self-administered to pharmacists. The questionnaire was made anonymous, and structured into four parts. The first part assessed demographics of respondents, second part was on attitude to pharmaceutical care, third part focused on practice and the fourth part was on barriers to practice and how to overcome them. The questionnaires contained open and closed questions. The essence of the open questions was for the respondents to volunteer additional information in the desired areas. The questionnaires were collated, and data fed into the computer and analyzed using Statistical Package for Social Sciences (SPSS Version 23). Results were presented as frequency and percentage of variables. Chi Square statistics was used to test for level of significance of attitude and practice. P-value of less than 0.05 was considered to be statistically significant.

\section{Scoring scale}

Scoring scale for attitude of respondents to pharmaceutical care was: $0-50 \%$ (Negative), $51-100 \%$ (Positive) while that of practice of pharmaceutical care was: $0-50 \%$, (Poor), 51$70 \%$ average, $71-100 \%$ (Good).

\section{RESULTS}

A total of 50 questionnaires were distributed, only 32 were returned, giving a response rate of $72 \%$. Majority of the respondents $(28.1 \%)$ were aged $50-59$ years, more than half $(62.5 \%)$ were males. The mean of the age was 40.5 years \pm 13.7 years. Majority of the respondents were married (71.9\%), more than half $(56.3 \%)$ had Bachelor of Pharmacy as sole degree. Exactly half $(50.0 \%)$ of the respondents were residing in Warri, nearly half $(40.6 \%)$ had been in practice for 1-5 years. Other demographic information about the respondents are contained in Table 1. Few (21.9\%) had attended more than six workshops on pharmaceutical care, about half (56.3\%) spent 2-3 days maximum outside their location to attend workshops on pharmaceutical care. About half $(53.1 \%)$ reported that they always applied pharmaceutical care in their practice. Few (28.1\%) sponsored themselves to workshops on pharmaceutical care. Majority (65.6\%) agreed that they will sponsor themselves to workshops on pharmaceutical care. Majority (56.3\%) spent maximum of 2-3 days to attend lectures on pharmaceutical care outside their location of practice. Nearly all (93.8\%) agreed they identified errors in patient prescriptions. Types of errors identified ranged from drug interactions and inappropriate prescriptions (9.4\%) each, duplicate therapy $(6.3 \%)$, dosage too high and dosage too low $(3.1 \%)$ each, combination of types of error $(53.1 \%)$ and all categories of errors (6.3\%). Methods used in monitoring patients included direct patient interview (50.0\%), blood pressure monitoring (12.5\%), documented test results from laboratories (6.3\%).

Reasons for not practicing pharmaceutical care ranged from lack of personnel (21.9\%), lack of collaboration with other healthcare providers $(18.8 \%)$, lack of space $(18.8 \%)$, non acceptance by physicians and nurses (18.8\%), lack of pharmaceutical care skills (9.4\%) and pharmaceutical care is time consuming $(6.5 \%)$. Suggestions on how to improve pharmaceutical care practice in the state included all pharmacists to acquire additional training in the Doctor of Pharmacy degree programme (12.5\%), pharmaceutical care should be taught in all schools of pharmacy $(6.3 \%)$, maintenance of privacy for patient counseling (9.4\%), improved professional relationship with patients $(3.1 \%)$, improved relationship with other healthcare providers (3.1\%), improved communication skills (6.3\%), and financial remuneration for pharmaceutical care activities carried out (3.1\%), and all of the above (50.0\%).

Analysis of sex of respondents versus number that monitored patients improvement was statistically significant at $\chi^{2}=9.931, \mathrm{P}=0.042$, with males $(62.5 \%)$ monitoring more than females (15.6\%). Analysis of marital status versus respondents that monitored improvement in patients condition was statistically significant at $\chi^{2}=16.072, \mathrm{P}=0.013$ with married respondents $(65.6 \%)$ monitoring better than singles $(21.9 \%)$ and widows (3.1\%). Analysis of marital status versus number of respondents that updated their knowledge regularly was statistically significant at $\chi^{2}=$ $32.768, \mathrm{P}=0.000$ with married respondents updating most (65.6\%), followed by singles (21.9\%). Analysis of marital status versus methods used in monitoring showed significance at $\chi^{2}=24.62, \mathrm{P}=0.003$ with married respondents using more of direct patient interviews (50.0\%), blood monitoring (12.5\%) than singles. Analysis of educational status versus number of respondents involved in identification of errors was significant at $\chi^{2}=21.013, \mathrm{P}=$ 0.002 with Bachelor of Pharmacy respondents (56.3\%) identifying more errors, followed by FPCPharm $(21.9 \%)$, Pharm. D. (12.5\%) and Masters (6.3\%). Analysis of town of practice versus types of errors identified was significant at $\chi^{2}$ $=41.621, \mathrm{P}=0.047$, with Warri identifying most $(50.0 \%)$, followed by Asaba (37.5\%), Ughelli (6.3\%) and Agbor (3.1\%) Analysis of educational status versus identification of errors was statistically significant at $\chi^{2}=21.013, \mathrm{P}=0.002$, with respondents with bachelor of pharmacy identifying most $(56.3 \%)$, followed by fellows $(21.9 \%)$, doctor of pharmacy $(15.6 \%)$ and masters (6.3\%). Analysis of age of respondents versus number documenting their pharmaceutical care activities was statistically significant at $\chi^{2}=18.469, \mathrm{P}=$ 0.048, with 50-59 years documenting most (28.1\%) followed by $40-49(25.0 \%), 30-39(21.9 \%) 20-29 \%$ (18.2\%) was least with more than 60 years. 
Table 1: Demographics of Respondents

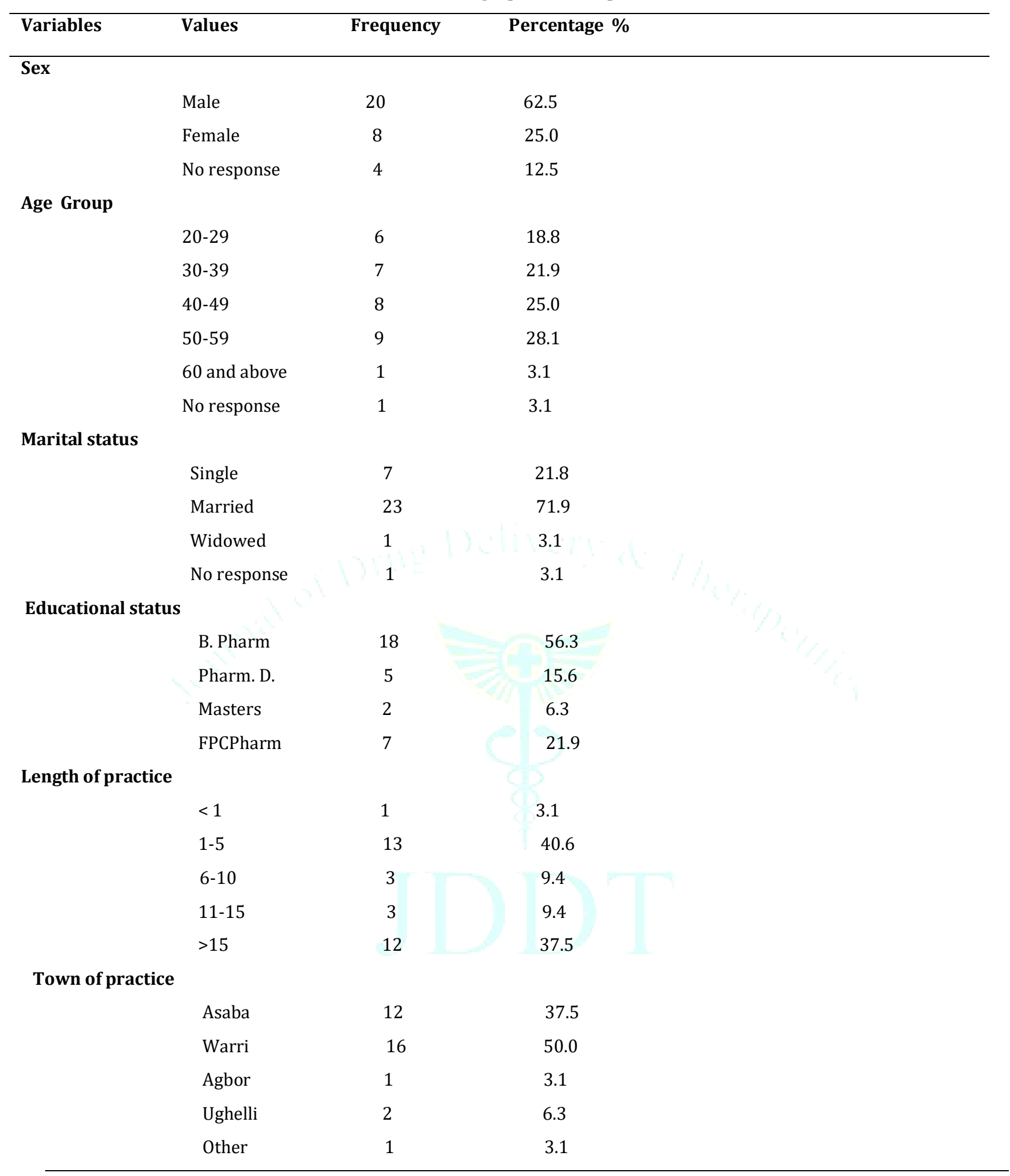


Table 2: Attitude of Respondents to pharmaceutical care

\begin{tabular}{|c|c|c|c|}
\hline Perception & Agree & Neutral & Disagree \\
\hline Do you think PC is a timely innovation to Pharmacy practice & $15(46.9)$ & $0(0)$ & $17(53.1)$ \\
\hline Do you think PC is not necessary in our practice & $0(0)$ & $21(65.6)$ & $11(34.4)$ \\
\hline Do you think PC will lead to better patient outcomes & $23(71.9)$ & $9(28.1)$ & $0(0)$ \\
\hline Do you think PC is very demanding in terms of time & $0(0)$ & $21(65.6)$ & $11(34.4)$ \\
\hline Willingness to sponsor yourself to workshops & $21(65.6)$ & $7(21.9)$ & $4(12.5)$ \\
\hline \multicolumn{4}{|l|}{ on PC outside location of practice } \\
\hline Do you sponsor yourself to training workshops on PC & $9(28.1)$ & $18(56.3)$ & $5(15.6)$ \\
\hline Do you think the knowledge you acquired from PC workshop & $21(51.6)$ & $9(28.1)$ & $2(6.3)$ \\
\hline \multicolumn{4}{|l|}{ improved your professional relationship with your patients } \\
\hline Do you apply PC to all your patients & $17(53.1)$ & $1(3.1)$ & $14(43.8)$ \\
\hline Total & $51.2 \%$ & $33.4 \%$ & $15.4 \%$ \\
\hline
\end{tabular}

PC--------Pharmaceutical care

Table 3: Practice of Pharmaceutical Care by Respondents

\begin{tabular}{lll}
\hline Attribute & Yes & No \\
\hline Monitoring improvement in patient response & $\mathbf{2 9}(90.6)$ & $\mathbf{3}(9.4)$ \\
Methods used in monitoring: & & \\
Direct patient interview & $16(50.0)$ & $16(50.0)$ \\
Blood pressure monitoring & $4(12.5)$ & $28(87.5)$ \\
Reported tests carried out on patients & $2(6.3)$ & $30(93.8)$ \\
Identification of errors in patient prescriptions & $\mathbf{3 0}(93.8)$ & $\mathbf{2 ( 6 . 3 )}$ \\
Counsel patients (with drug therapy problems) & $\mathbf{1 2 ( 3 7 . 5 )}$ & $\mathbf{2 0 ( 6 2 . 5 )}$ \\
Medication therapy management & $\mathbf{5 ( 1 5 . 6 )}$ & $\mathbf{2 7}(84.4)$ \\
Carry out medication review with patients & $\mathbf{3 ( 9 . 4 )}$ & $\mathbf{2 9}(\mathbf{9 0 . 6 )}$ \\
Carry out medication review with physicians & $\mathbf{9 ( 2 8 . 1 )}$ & $\mathbf{2 3 ( 7 1 . 9 )}$ \\
Documentation of pharmaceutical care activities & $\mathbf{1 4 ( 4 3 . 8 )}$ & $\mathbf{1 8}(56.3)$ \\
\hline Total & $\mathbf{3 9 . 0 \%}$ & $\mathbf{6 1 . 0 \%}$ \\
\hline
\end{tabular}


Table 4: Types of Errors identified

\begin{tabular}{lll}
\hline Error & Frequency & \multicolumn{1}{c}{ Percent } \\
\hline Dosage too high & 1 & 3.1 \\
Dosage too low & 1 & 3.1 \\
Inappropriate compliance & 3 & 9.4 \\
Duplicate therapy & 2 & 6.3 \\
More than 1 error & 17 & 53.1 \\
All & 2 & 6.3 \\
No response & 3 & 9.4 \\
Total & $\mathbf{3 2}$ & $\mathbf{1 0 0 . 0}$ \\
\hline
\end{tabular}

Table 5: Factors associated with monitoring patients' improvement among respondents.

\begin{tabular}{lcccc}
\hline Variable & $\chi^{2}$ & ${ }^{*} \mathrm{P}$ & $\begin{array}{c}\text { (\%) Respondents } \\
\text { that monitor patients improvement }\end{array}$ & Inference \\
\hline Sex & 9.931 & 0.042 & & \\
Males & & & 62.5 & \\
Females & & & 16.6 & Statistically significant \\
& & & & \\
Marital status & 16.072 & 0.013 & & \\
Married & & & 65.6 & \\
Singles & & & 21.9 & \\
Divorced & & & & \\
Widowed & & 3.1 & \\
\hline
\end{tabular}

Table 6: Reasons for not practicing Pharmaceutical care by Respondents

\begin{tabular}{llll}
\hline Attribute & Yes & \multicolumn{3}{c}{ No } & No \\
& \multicolumn{3}{c}{ Response } \\
\hline Fear of change & 0 & $3(9.4)$ & $29(90.6)$ \\
Lack of pharmaceutical care skills & $3(9.4)$ & $3(9.4)$ & $26(81.3)$ \\
Lack of collaboration with other healthcare providers & $6(18.8)$ & $3(9.4)$ & $23(23)$ \\
Lack of space & $6(18.8)$ & $2(6.3)$ & $24(75.0)$ \\
Non acceptance by physicians and nurses & $6(18.8)$ & $2(6.3)$ & $24(75.0)$ \\
Pharmaceutical care is time consuming & $2(6.3)$ & $3(9.4)$ & $26(81.3)$ \\
Lack of personnel & $7(21.9)$ & $2(6.3)$ & $23(71.9)$ \\
\hline
\end{tabular}

Table 7: Number of workshops attended on Pharmaceutical care

\begin{tabular}{lcc}
\hline Number of workshops attended & Frequency & Percentage (\%) \\
\hline None & 9 & 28.1 \\
1 & 2 & 6.3 \\
$2-5$ & 13 & 40.6 \\
6 and above & 7 & 21.9 \\
No response & 1 & 3.1 \\
\hline
\end{tabular}




\section{DISCUSSION}

The results of this study are quite interesting and agree with studies from other parts of the world. 7,13,18,20,39 There were more males than females in this study, which is similar to results of other studies.13,39 Majority of respondents were aged 50-59 years, while most had been in practice for 1-5 years. This result differs slightly from a similar study in Asaba ${ }^{13}$ which had majority aged $31-40$ years and length of practice of $1-10$ years. Half of the respondents were practicing in Warri, the commercial capital of the state.

In this study, attitude of respondents to pharmaceutical care was positive $(51.2 \%)$. The result is in line with those of several studies.6, 18,20 For instance the Survey of Attitude, Perception and Practice of Pharmacists in Ogun State, SouthWestern Nigeria ${ }^{20}$ on Pharmaceutical Care Implementation revealed that attitude of pharmacists towards implementation of Pharmaceutical care was good. The result also agrees with the study carried out in Benin City which concluded that the attitudes of Nigerian pharmacists towards Pharmaceutical care were favorably high irrespective of the practice settings. It also agrees with the Kaduna Study 18 which recorded a positive attitude to Pharmaceutical care. This is also in agreement with the study 6 among University of Nigeria Pharmacy students which revealed positive attitude among them.

Practice of pharmaceutical care recorded in this study was poor (39.0\%). This result is similar to that of an earlier study conducted in Asaba 13 which recorded a poor practice of $50.8 \%$. It is also similar to the Kaduna study 18 which recorded a deficit in practice of pharmaceutical care. It is interesting to note that in this study nearly all respondents (93.8\%) were involved in identification of errors in patient prescriptions. Overall however, practice was poor.

One reason for the poor practice of pharmaceutical care recorded in this study may have been the fact that more than half of respondents in this study $(56.3 \%)$ were sole holders of the Bachelor of Pharmacy degree, and they may not have acquired the necessary skills to practice pharmaceutical care which is taught extensively at the post graduate school and doctor of pharmacy degree programmes, while few (21.9\%) were fellows of the West African Post Graduate College of Pharmacists and very few (15.6\%) were holders of the Doctor of Pharmacy Degree. This study also revealed that more males were involved in monitoring of patient improvement than females, with married respondents monitoring more than singles. Also, most respondents with Bachelor of Pharmacy degree identified the highest number of drug therapy problems, probably because they were much higher in number $(56.3 \%)$ than others. They also updated their knowledge more, which is to be expected. Most respondents practicing in Warri, the commercial capital of the state identified the most types of prescription errors than those practicing in rural settings and this could be explained by the fact that Warri has huge population ${ }^{38}$ and several hospitals, and there is a possibility that the respondents there had higher access to patients with prescriptions from hospitals than those in rural settings. In this study, patients in the age bracket 50-59 years showed the highest level of documentation of pharmaceutical care activities compared to other age groups. Also, more married respondents updated their knowledge than singles $(\mathrm{P}=$ 0.000)

Reasons for not practicing pharmaceutical care ranged from lack of personnel $(21.9 \%)$, lack of collaboration with other healthcare providers $(18.8 \%)$, lack of space $(18.8 \%)$, non acceptance by physicians and nurses $(18.8 \%)$, lack of pharmaceutical care skills (9.4\%) and pharmaceutical care is time consuming. (6.5\%). These barriers recorded in this study are similar to reasons adduced for non practice of pharmaceutical care from other studies carried out elsewhere in the world. ${ }^{13,18,20}$ For instance a study ${ }^{7}$ found out that lack of involvement of pharmacists is one of the barriers to effective implementation of pharmaceutical care services in community pharmacies in Nigeria. Other studies concluded that limited consulting time, lack of private counseling area at the community pharmacies, perception that patients are not willing to pay for specialized care, and unfriendly inter-professional dispositions, have limited the growth of pharmaceutical care practice in Nigeria especially at the community pharmacy level which are all in agreement with this study. $6,10,11,12,13$

\section{CONCLUSION}

This study revealed positive attitude but poor practice of pharmaceutical care among community pharmacists in Delta State as at the time of Study (2017). Barriers to practice of pharmaceutical care ranged from lack of personnel, lack of collaboration with other healthcare providers, lack of space, non acceptance by physicians and nurses and lack of pharmaceutical care skills.

Educational interventions such as more pharmacists going back to acquire additional training via the Doctor of Pharmacy degree would go a long way to improve the practice of pharmaceutical care in the state. Also, all schools of pharmacy in the country should be encouraged to implement the doctor of pharmacy curriculum in line with the approval by the National Universities Commission. Community pharmacists in the state should be encouraged to create confidential rooms for maintenance of privacy for patient counseling. They should also endeavour to improve professional relationship with their patients, other healthcare providers and improve their communication skills as well.

\section{Limitations of Study}

This study was carried out with the use of questionnaires only. It was not possible to directly observe the level of implementation of pharmaceutical care by the respondents since they were not interviewed in their places of practice.

\section{Acknowledgement}

The authors are grateful to the Executive Committee of the Delta State Branch of the Association of Community Pharmacists of Nigeria (ACPN) for the permission to carry out this research on their members. We are also grateful to Dr. Val Odili PhD of the Department of Clinical Pharmacy and Therapeutics, University of Benin, Benin City for agreeing to proof read this work.

\section{Conflict of Interest}

The researchers declare no conflict of interest. 


\section{REFERENCES}

1. Hepler DD, Strand LM, Opportunities and Responsibilities in Pharmaceutical Care, Am.J. Pharm.Educ.1989; 53, 7S-15S

2. University of Oklahoma College of Pharmacy. Definition of Pharmaceutical Care. Available at https://pharmacyold.ouhsc.edu Accessed 17th November, 2017

3. Foppe van Mill JW, Fernandez Llimos F. What is 'pharmaceutical care' in 2013? Pharm Pract (Granada) 2013 Jan-March; 11(1):1-2

4. Foppe van Mil JW, Schulz M. A review of pharmaceutical care in community pharmacy in Europe. Harvard Health Policy Review 2006; 7 (1): 155-168.

5. FIP Statement of Pharmaceutical Standards Pharmaceutical care. Council meetingin Hague, Netherlands on 4 September, 1998.

6. Udeogaranya PO, Ukwe CV, Ekwunife OI. Assessment of attitudes of University of Nigeria pharmacy students towards pharmaceutical care. 2009. www.pharmacytimes.com/.org (Accessed $5^{\text {th }}$ June, 2018)

7. Ogbonna BO, Ejim CE, Ikebudu CC, Uzodinma SU, Orji CE. Pharmaceutical Care and Community Pharmacy Practice In Nigeria; Grappling With the Frontier. European Journal of Pharmaceutical and Medical Research ejpmr, 2015; 2(7): 33 42

8. WHO. The Role of the Pharmacist in the Healthcare System https://apps.who.int Accessed 13 $3^{\text {th }}$ October, 2019

9. May RJ. Barriers to pharmaceutical care in the acute care setting. Am J Hosp Pharm., 1993; 50: 1608-11.

10. Swift BG. Barriers to pharmaceutical care in the home care setting. Am J Hosp Pharm., 1993; 50: 1611-4.

11. Louie N, Robertson N. Barriers to pharmaceutical care in the managed care setting. Am J Hosp Pharm., 1993; 50: 1614-7.

12. Desselle S, Rappaport HM. The identification of pharmaceutical care standards in the community pharmacy setting. J Pharm Care., 1997; 1(3): 1-11

13. Amibor KC, Onyegasi CS, Ezeudu PI. Knowledge, Attitude and Practice of Pharmaceutical Care among pharmacists in a state in Nigeria. African Journal of Pharmaceutical Research and Development. 2018 ; 10 (1) 22-31

14. Dunlop JA, Shaw JP. Community pharmacists' perspectives on pharmaceutical care implementation in New Zealand. Pharmacy World and Science 2002;24(6), 224-230

15. Fang Y, Shimin Y, Bianling F, Yufei N, Kanghuai Z. Pharmacists' perception of pharmaceutical care in community pharmacy: a questionnaire survey in Northwest China. Health and Social Care in the Community (2011) 19(2), 189-197

16. Oparah CA, Eferakeya AE. Attitude of Nigerian pharmacists towards pharmaceutical care. Pharm World Sci., 2005; 27(3): 208-14.

17. Oparah CA, Enato EFO, Akoria OA. Assessment of patient satisfaction with pharmaceutical services in a Nigerian teaching hospital. Int J Pharm Pract., 2004; 12: 255-260.

18. Ma'aji HU, Ondeku S.I. Assessment of Knowledge, Attitude, and Practice of Community Pharmacists towards Pharmaceutical Care in Kaduna State, Nigeria. IJPTP, 2014; 5(2): 972-976.

19. Oparah AC; Essentials of Pharmaceutical Care. A Cybex publication, 2010; 4-38.

20. Suleiman IA, Onaneye O. Pharmaceutical Care Implementation: A Survey of Attitude, Perception and Practice of Pharmacists in Ogun State, South-Western Nigeria, International Journal of Health Research, June 2011; 4(2): 9197
21. Pauley TR, Magee MJ, and Curry JD. Pharmacist Coordinated Asthma Management Programme. Am Pharmacother., 1995; 29: 5-9.

22. Yancey V, Yakimo R, Perry A, McPherson TB. Perceptions of pharmaceutical care among pharmacists offering compounding services. J. Am Pharm Assoc 2003; 48(4):505-14

23. Desselle S. Pharmacists' Perceptions of a Set of Pharmaceutical Care Practice Standards Journal of the American Pharmaceutical Association 1997; 37 (5) 529-534

24. El Hajj MS, AL-Saeed HS, Khaja M. Qatar pharmacists' understanding, attitudes, practice and perceived barriers related to providing pharmaceutical care. Int J Clin Pharm 2016; 38: 330

25. Westerlund LT, Bjo "rk HT. Pharmaceutical care in community pharmacies: practice and research in Sweden. The Annals of Pharmacotherapy 2006; 40 (6): 1162- 1169

26. Eickhoff C, Schulz M. Pharmaceutical care in community pharmacies: practice and research in Germany. The Annals of Pharmacotherapy 2006; 40 (4): 729-735.

27. Jones EJ, Mackinnon NJ, Tsuyuki RT. Pharmaceutical care in community pharmacies: practice and research in Canada. The Annals of Pharmacotherapy 2005; 39 (9): 1527-1533.

28. Surachat N, Shu CL. Thai pharmacists' understanding, attitudes, and perceived barriers related to providing pharmaceutical care. American Journal of Health System Pharmacy 2006; 63: 2144-2150.

29. De Castro MS, Correr CJ. Pharmaceutical care in community pharmacies: practice and research in Brazil. The Annals of Pharmacotherapy 2007; 41 (9): 1486-1493.

30. Pauley TR, Magee MJ, and Curry JD. Pharmacist Coordinated Asthma Management Programme. Am Pharmacother., 1995; 29: 5-9.

31. WHO Consultative Group on the Role of the Pharmacist in the Health Care System. (1988: New Delhi, India). Available at https://apps.who.int/iris/handle/10665/59169 Accessed $11^{\text {th }}$ June, 2019

32. Martı 'n-Calero MJ, Machuca M, Murillo MD, Cansino J, Gastelurrutia MA, Faus MJ. Structural process and implementation programmes of pharmaceutical care in different countries. Current Pharmaceutical Design 2004; 10 (31): 3969-3985.

33. Oparah AC, Adje DU, Enato EFO Outcomes of pharmaceutical care intervention to hypertensive patients in a Nigerian community pharmacy International Journal of Pharmacy Practice 2010. 14 (2) 05

34. National Population Commission. Delta State. Available at www.population.gov.ng Accessed 15th September, 2017

35. Amibor KC, Obaseki OA, Onyegasi OS, Onochie TI, Apeh DE, Ujomu AC. Knowledge, attitude and preparedness of pharmacists towards epidemic outbreaks. West African Journal of Pharmacy. 201526 (2) 17

36. Odili VU, Amibor KC, Obaseki AO. Internet and social media use among pharmacists in a state in Nigeria Journal of Drug Delivery and Therapeutics 20199 (6) 95-101

37. About Asaba. Available at https://asaba.com Accessed 17th August, 2018

38. Warri. https://en.m/wikipedia.org .wiki Accessed 27th October, 2019

39. Inamdar SZ, ApsyP, Rosy J, Kulkarni RV, Gazala K, Kavaya H. et al. Assessment of Knowledge, Attitude and Practice of Community Pharmacist towards the provision of Pharmaceutical Care: A Community based Study. Indian Journal of Pharmacy Practice 2018. 11 (3)158-163 